\title{
O Alinhamento entre Argentina e Estados Unidos na Política Externa de Menem
}

\author{
Argentina's alignment with the United States \\ in Menem's Foreign Policy
}

Mauricio Santoro*

\section{Resumo}

O presidente Carlos Menem adotou uma política externa baseada no alinhamento da Argentina com os Estados Unidos. A aproximação foi expressiva, resultando em maior engajamento econômico e na eliminação de conflitos. Contudo, houve vários pontos aquém das expectativas, devido a contradições comerciais e políticas entre os dois países.

Palavras-chave: Argentina; Estados Unidos, política externa, alinhamento, realismo periférico.

\begin{abstract}
President Carlos Menem adopted a foreign policy based upon the alignment of Argentina with the United States. The rapprochement was meaningful, resulting in more economic engagement and in the elimination of conflicts. However, there were many points below the expectations, because of commercial and political contradictions between the two countries.
\end{abstract}

Keywords: Argentina; United States, foreign policy, alignment, peripheral realism.

* Doutor em Ciência Política pelo IUPERJ Professor-adjunto do Departamento de Relações Internacionais da UERJ. 


\section{Introdução}

No governo de Carlos Menem (1989-1999), a Argentina implementou a doutrina de política externa do realismo periférico. Formulada por intelectuais próximos ao presidente, ela se baseava numa crítica liberal da diplomacia do país após a Segunda Guerra Mundial, contestando o modelo de desenvolvimento da industrialização por substituição de importações e as relações conflituosas com os Estados Unidos e o Brasil. Preconizava que, no pós-Guerra Fria, a Argentina deveria adotar o alinhamento com Washington como pré-condição para a retomada do crescimento econômico e usar a integração com o Brasil como modo de contrabalancear essa influência (CISNEROS e PIÑEIRO IÑIGUEZ, 2000; DE LA BALZE, 1995, 1997 e 2000; ESCUDÉ, 1992; RUSSELL e TOKATLIAN, 2003).

Este artigo examina as relações da Argentina com os Estados Unidos durante o governo Menem com o objetivo de avaliar se o alinhamento buscado pelos teóricos do realismo periférico foi alcançado e quais foram os resultados do relacionamento bilateral entre Buenos Aires e Washington, com ênfase nos impactos para a economia e para a segurança internacional.

0 teórico das relações internacionais Stephen Walt afirma que os Estados buscam alianças para se defender de uma ameaça militar comum. Evidentemente, não era a situação da Argentina do realismo periférico. O país não tinha inimigos contra os quais precisasse se proteger. Mas esse autor sugere que Estados fracos podem buscar a adesão ideológica à nação dominante como meio de se fortalecerem no sistema internacional. (WALT, 1987, p. 39). No caso do menemismo, os vínculos com Washington tiveram importância fundamental nas disputas domésticas, dando apoio à implementação da agenda política da coalizão governista.

A formulação do realismo periférico é inseparável da crítica ao modelo de substituição de importações e da adesão à nova ordem econômica na qual a América do Sul se inseriu após a crise da dívida externa. O governo Menem priorizou o uso da diplomacia como ferramenta para consolidar as medidas pró-mercado, ressaltando a importância de reconquistar a credibilidade nos mercados financeiros globais para renegociar a divida externa e gerar melhores possibilidades de investimento e de comércio.

A primeira seção deste artigo trata da formulação do realismo periférico, analisando seus principais postulados teóricos. A segunda examina como a doutrina foi aplicada na prática, com foco nos atos das autoridades argentinas e as consequências de suas decisões no campo das relações econômicas com os Estados Unidos.

A questão da credibilidade aplica-se não somente às reformas econômicas, mas também ao campo da segurança internacional, tema da seção seguinte. A política externa argentina, nesse aspecto, foi baseada na eliminação de zonas de atrito com os Estados Unidos, mas igualmente na necessidade de encontrar um novo papel para as Forças Armadas, depois dos anos turbulentos dos regimes autoritários. Tais objetivos explicam as decisões da Argentina, como a participação em dezenas de missões de paz da ONU, em operações multinacionais como a Guerra do Golfo, a intervenção no Haiti, e ainda a assinatura dos tratados de desarmamento em tecnologias avançadas como a nuclear.

No entanto, foram precisamente as tensões nas relações entre civis e militares que impossibilitaram a Argentina de cooperar integralmente com os Estados Unidos no combate 
às chamadas "novas ameaças", sobretudo ao narcotráfico. O terrorismo também ilustrou as contradições do governo Menem. Nos anos 1990, dois atentados atribuídos ao Hezbollah em Buenos Aires deixaram centenas de mortos. Contudo, apesar da importância do tema na agenda de segurança de Washington, mesmo antes dos ataques do 11 de Setembro, as autoridades menemistas não foram capazes de enfrentar a situação, envolvidas em escândalos de corrupção que paralisaram as investigações sobre os atentados. A seção examina ainda os motivos que inspiraram a tentativa do governo argentino em ingressar na Organização do Tratado do Atlântico Norte e a resposta que essa iniciativa obteve por parte dos Estados Unidos.

\section{Os Pressupostos Teóricos do Realismo Periférico}

O realismo periférico foi formulado ao longo das décadas de 1980 e 1990 por um grupo de acadêmicos que estudavam a inserção internacional argentina desde a ascensão do peronismo, quando o país abandonou o tradicional alinhamento com a Grã-Bretanha e adotou posições críticas quanto à nova ordem global que se articulava sob a liderança dos Estados Unidos. O mais influente desses intelectuais, o historiador Carlos Escudé, argumentava que Perón e seus seguidores tinham falado em compreender o cenário diplomático que se consolidava e que isso teve consequências negativas para o crescimento econômico da Argentina, em contraste com o Brasil, que se adaptou melhor ao mundo pós-Segunda Guerra e procurou manter melhores relações com Washington (ESCUDÉ, 1983).

O autor também é bastante crítico dos sucessores de Perón, em particular da ditadura de 1976-1983, que teria tido a pretensão de adotar uma diplomacia de grande potência sem dispor dos recursos para tal - o grande exemplo desse fracasso foi a derrota argentina para os britânicos na guerra das Malvinas (ESCUDÉ, 1992: 18).

Escudé propõe um modelo de política externa, que ele chama de "realismo periférico", isto é, o realismo de um país que ele entende como pobre e pouco relevante na ordem internacional, "afetado por uma overdose crônica de confrontações ao longo de meio século" (ESCUDÉ, 1992: p. 24) e que deveria restringir suas divergências com a potência dominante apenas a temas que impactassem diretamente seus interesses econômicos. O autor é crítico das abordagens nacionalistas e preconiza o alinhamento da Argentina aos Estados Unidos como pré-condição para a retomada de seu crescimento.

Embora Escudé não apresente em seus livros uma plataforma econômica, ele juntou-se ao governo de Carlos Menem como assessor do ministro das Relações Exteriores Guido di Tella. Nessa condição, ele participou das reformas liberais do presidente e da busca por estabelecer o que o chanceler chamava de "relações carnais" com os Estados Unidos.

O nexo entre política externa e reformas econômicas é mais claro na obra de outros autores vinculados ao realismo periférico, em particular o economista Felipe de la Balze. Para ele, os pontos essenciais da diplomacia argentina eram as relações com os Estados Unidos e o Brasil, numa lógica que privilegiava a integração comercial e a eliminação de contenciosos (DE LA BALZE, 1995 e 1997). 
Tal como Escudé, o economista defende o alinhamento com os Estados Unidos, entendendo na grande potência o parceiro-chave para a Argentina. Contudo, ele acrescenta que essa relação precisa ser contrabalanceada pela integração com o Brasil e que esse seria o passo inicial para acordos comerciais com outros países da América Latina (DE LA BALZE, 1995).

Os pressupostos do realismo periférico foram muito criticados por acadêmicos argentinos de várias correntes. Eles seriam fruto de uma "visão enganosa e reducionista" (RUSSELL e TOKATLIAN, 2003: 52), que desvalorizava os esforços necessário para aumentar a autonomia econômica e tecnológica e não levava em conta a trajetória diplomática do Brasil, que desde a década de 1960 havia rompido com o alinhamento com os Estados Unidos e buscado mais liberdade de ação, ao ponto de às vezes parecer para o governo Menem um aliado "economicamente necessário, mas politicamente inconveniente" (RUSSELL e TOKATLIAN, 2003: 54).

Os autores da escola neoestruturalista, muito influenciada pelos estudos da Comissão Econômica da ONU para América Latina e Caribe (CEPAL), criticavam a visão histórica do realismo periférico como afetada pela nostalgia de um "paraíso perdido fundado no sistema agroexportador e na ideologia livre-cambista" (FERRER, 1998: 73) e de não refletir acerca das lutas políticas da Argentina para romper com a dependência britânica daquela época e estimular o desenvolvimento industrial (RAPOPORT, 2006). Os neoestruturalistas favoreciam as relações com os outros países latino-americanos, em particular o Brasil, como eixo central da diplomacia argentina.

As próximas duas seções analisam como os pressupostos teóricos do realismo periférico funcionaram na prática, nas questões econômicas e nos temas de segurança internacional, e como a realidade da diplomacia fez com que a Argentina se defrontasse com problemas que não haviam sido previstos pelos acadêmicos que formularam essa doutrina.

\section{Finanças, comércio e investimentos}

O realismo periférico buscou sua justificação em termos econômicos. Alinhar-se a Washington traria prosperidade à Argentina, de certo modo replicando a "relação especial" que o país desfrutara com a Grã-Bretanha durante a primeira metade do século XX. Contudo, apesar dos esforços do governo Menem, os resultados ficaram aquém do esperado. A dívida externa foi renegociada, os investimentos americanos aumentaram bastante e houve ganhos no comércio, mas o mercado dos Estados Unidos nunca se tornou o destino preferencial das exportações argentinas, que se direcionaram sobretudo para o Brasil (MRE, 1999).

A divida externa havia sido o principal problema das relações econômicas internacionais da Argentina durante os anos 1980. A exemplo de outros países em desenvolvimento, sofrera com o efeito cascata decorrente da alta dos juros americanos. Escudé criticou o presidente Raúl Alfonsín (1983-1989) pela "politização" da divida. Na sua visão, o ex-mandatário errara ao se juntar ao Grupo de Cartagena e tentar uma negociação conjunta. 0 melhor teria sido aceitar as

1 Coalizão que reunia os 11 países mais endividados da América Latina e que tentou, sem sucesso, estabelecer melhores condições de negociar suas dívidas com os credores externos. 
novas regras do jogo e então, valendo-se da boa vontade americana, buscar um acordo com os credores (ESCUDÉ, 1992).

Esse programa foi colocado em prática no governo Menem. O presidente argentino utilizou a implementação de seu programa de reformas neoliberais como prova de que queria transformar a economia do país e pediu ajuda ao governo americano para resolver as pendências com o FMI. O argumento é que um acordo com a organização fortaleceria o impulso para a abertura da economia. 0 ponto decisivo veio em 1992 e é ilustrado por um editorial do jornal argentino Clarín:

Esse respaldo veio três dias depois que, em um café da manhã, Menem dissera a Nicholas Brady [secretário do Tesouro americano]: "Diga-me, depois de todos os esforços que fizemos para ajustar nossa economia lhe parece que posso voltar à Argentina de mãos vazias?" Brady sentiu a pressão, recordando que a administração Bush havia tomado a decisão política de apoiar o programa econômico argentino e enviou o sinal respectivo ao FMI (...) A decisão política tomada por Bush foi mais forte do que as objeções que os técnicos do fundo e a banca dos credores fazem a Cavallo pelo não cumprimento de algumas metas previstas principalmente no terreno fiscal - para que a Argentina ingresse "limpinha, limpinha" no plano Brady. (Apud CORIGLIANO, 2003b, p. 283)

A estratégia de Menem foi bem-sucedida e a Argentina conseguiu renegociar sua dívida por meio da diminuição e a "securitização" dos débitos, convertidos em títulos lançados ao mercado financeiro. Ao longo da década, os papéis argentinos ganharam grande destaque nesse meio e para a comunidade das finanças internacionais o país se tornou um modelo no mundo em desenvolvimento. Ironicamente, isso fez com que o FMI adotasse atitudes complacentes diante de vários problemas econômicos, com consequências graves para a crise de 2001 (BLUSTEIN, 2005).

A aproximação com os Estados Unidos de fato serviu para conquistar a confiança dos investidores, com repercussões positivas nos círculos financeiros internacionais. Espanha, Itália, França e Chile investiram bastante na Argentina, que concentrou 40\% dos títulos dos mercados emergentes: "Para firmas com pretensões de alcance global, era essencial ter negócios significativos na América Latina, preferencialmente com experiência 'de campo', especialmente nos três grandes mercados - México, Brasil e Argentina" (BLUSTEIN, 2005, p.30). Os principais bancos de investimento organizavam excursões ao país, apresentando a sofisticação cultural de Buenos Aires como prova da segurança para o ambiente empresarial e financeiro.

O governo argentino assinou diversos acordos econômicos com Washington, visando à eliminação de entraves burocráticos ao comércio e ao aumento da proteção aos investimentos americanos - por exemplo, oferecendo garantia de que não seriam nacionalizados. 0 comércio bilateral aumentou 200\% durante a primeira presidência de Menem (1989-1995). Contudo, o mercado americano nunca representou mais de 10\% das exportações argentinas, com o Brasil sendo destino do triplo desse montante (MRE, 1999).

Os produtos da Argentina enfrentavam diversas barreiras para entrar nos Estados Unidos. A carne tinha sua importação proibida desde 1926, por pretextos sanitários, mas muito mais 
pela ação do lobby agropecuário americano. Outras medidas protecionistas, como os subsídios ao trigo, prejudicavam os fazendeiros argentinos. A lã, couro e aço também se deparavam com sobretaxas. Tais produtos, junto aos minérios e ao petróleo, concentram cerca de 2/3 de suas exportações. Por isso, apesar do entusiasmo nos discursos dos líderes políticos, os negociadores comerciais da Argentina não mantinham grandes expectativas nos acordos com Washington e acreditavam que as possibilidades eram melhores na Rodada Uruguai do Acordo Geral de Tarifas e Comércio (GATT), de 1986 a 1994 (e posteriormente, na Organização Mundial do Comércio).²

Em outras palavras, a Argentina não era o México, cuja maioria das exportações já iam para os Estados Unidos antes da assinatura do Nafta. Para a elite mexicana, o alinhamento com Washington se vincula a uma situação já existente de dependência econômica com relação ao vizinho do Norte. 0 acordo de livre comércio procurava criar facilidades para consolidar o México em plataforma de exportações ao mercado americano. Tal estratégia era impossível na Argentina, cujo comércio exterior era composto majoritariamente por mercadorias que competiam com a produção doméstica americana.

As limitações foram claras no caso da carne. A criação agropecuária é elemento essencial da economia argentina. A relação especial com a Grã-Bretanha fora construída em grande parte a partir da exportação de carne para o império britânico. Menem esforçou-se para revogar a proibição americana à importação de carne argentina, o que finalmente obteve em 1996, com cota de 20 mil toneladas ao ano. Contudo, a vitória foi pouco mais do que retórica: os subsídios aos criadores de gado concedidos pelo governo americano colocavam seus rivais da América do Sul em posição desvantajosa para disputar o mercado.

Além das negociações comerciais propriamente ditas, é preciso observar outros fatores da economia argentina. Historicamente, a política cambial foi o elemento decisivo para os desequilíbrios do comércio exterior do país³. Nos anos 1990, a combinação do 1:1 da conversibilidade com a diminuição das tarifas teve um impacto devastador. 0 desequilíbrio era motivado por razão simples: os Estados Unidos tinham muito mais a vender, e produtos de maior valor agregado, do que a Argentina podia Ihes oferecer. Relatório da chancelaria argentina reconhece claramente o problema:

Deve-se mencionar, apesar disso, que o saldo da balança comercial [com Washington] tem sido tradicionalmente desfavorável para a Argentina, especialmente durante os anos de crescimento econômico, devido ao fato de que os Estados Unidos são um fornecedor habitual de bens de capital. 0 déficit acumulado no período de 1991-1998 foi ao redor de US\$19 bilhões. (MRE, 1999, p. 35)

Os dados do comércio bilateral mostram o déficit crescente:

2 Elvio Baldinelli, ex-secretário de Comércio Exterior e ex-embaixador da Argentina junto à União Europeia. Entrevista ao autor em Buenos Aires, janeiro de 2007.

3 Entrevista ao autor de Elvio Baldinelli, ex-secretário de Comércio Exterior e embaixador da Argentina junto à Comunidade Econômica Europeia. Buenos Aires, 2007. 
Tabela 1: Comércio entre Argentina e Estados Unidos, 1991-1999

\begin{tabular}{|c|c|c|c|}
\hline Ano & $\begin{array}{c}\text { Exportações aos Estados Unidos } \\
\text { (em bilhões de dólares) }\end{array}$ & $\begin{array}{c}\text { Importações dos Estados Unidos } \\
\text { (em bilhões de dólares) }\end{array}$ & $\begin{array}{c}\text { Saldo } \\
\text { (em bilhões de dólares) }\end{array}$ \\
\hline 1991 & 1,21 & 1,84 & $-0,63$ \\
1992 & 1,32 & 2,46 & $-1,14$ \\
1993 & 1,26 & 3,07 & $-1,81$ \\
1994 & 1,73 & 4,37 & $-2,64$ \\
1995 & 1,80 & 4,20 & $-2,40$ \\
1996 & 1,97 & 4,74 & $-2,77$ \\
1997 & 2,20 & 6,09 & $-3,89$ \\
1998 & 2,21 & 6,22 & $-4,01$ \\
\hline 1999 & 2,65 & 4,99 & $-2,34$ \\
\hline
\end{tabular}

Fonte: Instituto Nacional de Estadísticas y Censos de la República Argentina (Indec), 2008

A escassez de divisas que o déficit provocava se tornou um problema sério no fim dos anos 1990, quando não pôde mais ser contrabalanceada pelo fluxo de investimentos que visava às privatizações. 0 desequilíbrio na balança comercial também provocou tensões no Mercosul, onde o governo Menem tentava compensar os prejuízos da relação com Washington.

Ainda assim, a política externa continuou a buscar maior integração comercial com os Estados Unidos, sobretudo pela via de um acordo continental. Quando o presidente George Bush Sênior lançou em 1991 sua proposta de livre-comércio regional, a "Iniciativa para as Américas", a resposta do chanceler Guido Di Tella foi nos moldes dos cânones do realismo periférico: "Temos que marchar, sim ou sim, ao continentalismo do Alasca à Terra do Fogo" (Apud SACCONE, 1994, p. 115).

Entretanto, os diplomatas argentinos tinham consciência de que as enormes assimetrias de poder existentes entre seu país e os Estados Unidos tornavam impossíveis as negociações bilaterais. A estratégia adotada foi utilizar a integração regional, via Mercosul, para obter melhores condições. Assim, foi assinado em Washington o "Acordo 4+1" pelo qual os sócios do bloco se comprometiam a tratar da liberalização comercial continental adotando posições unificadas. Em termos práticos isso significava uma postura mais cética em relação ao continentalismo, pois as estratégias do Mercosul se subordinavam às necessidades de proteção do parque industrial brasileiro.

No contexto do início dos anos 1990, o Acordo 4+1 também representou a vitória do Itamaraty diante da ideologia liberalizante que predominava no governo Fernando Collor. O embaixador brasileiro Paulo Nogueira Batista afirmou que o presidente agiu bem ao:

não aceitar discutir com Bush a formação da área de livre-comércio das Américas, 'de contornos mal definidos', mas com suficiente imantação, pelo simples anúncio, 'para atrair individualmente vários países latino-americanos e perturbar processos de integração subregional'”. (Apud MONIZ BANDEIRA, 2003, p. 485) 
Porém, as propostas americanas conseguiram exatamente isso. A entrada em vigor do Nafta, em 1994, atraiu países da América do Sul que se empenhavam em processos de liberalização comercial e queriam acesso facilitado ao mercado americano, ao mesmo tempo em que temiam a concorrência do México como plataforma de exportações baratas. Argentina e Chile se interessaram por um acordo nos moldes do Nafta, ou pela inserção nesse bloco, e tinham expectativas de que isso ocorreria no curto prazo.

As razões pelas quais tal fato não aconteceu estão relacionadas principalmente à política doméstica dos Estados Unidos. Tradicionalmente, o país havia sido refratário aos acordos bilaterais ou regionais de livre-comércio. Na grande onda de liberalização iniciada após a Segunda Guerra Mundial, os americanos preferiram apostar no multilateralismo do GATT. A postura era outra quanto às soluções regionais:

Julgavam-nos discriminatórios e tendentes a debilitar o esforço para atingir um sistema multilateral mais livre. Foi apenas por motivos políticos - a necessidade de conter o expansionismo soviético durante a Guerra Fria - que os americanos aceitaram o Tratado de Roma, que criou em 1957 o Mercado Comum Europeu. (RICUPERO, 2003, p. 17)

A situação só mudou em meados dos anos 1980, quando Washington, pressionada pelo déficit comercial crescente com a Ásia e a Europa, buscou reforçar sua posição em outros mercados. Em 1985, assinou um acordo de livre-comércio com Israel. Em 1988, foi a vez do Canadá, numa negociação que logo foi expandida para incorporar o México. Também pesaram as dificuldades enfrentadas no sistema multilateral, com os impasses na Rodada Uruguai do GATT. Problemas que cresciam à medida em que a instituição incorporava temas como agricultura, propriedade intelectual e serviços.

A Cúpula de Miami, em 1994, na qual foi lançada a proposta da Área de Livre Comércio das Américas (ALCA), marcou o auge da adesão americana aos acordos regionais. Tal situação mudou rapidamente. A crise mexicana estourou logo após a entrada em vigor do Nafta e despertou receios em vários setores sociais da opinião pública americana, que julgavam perigosa uma integração mais profunda com as instáveis economias da América Latina. No Partido Democrata, grupos ligados a sindicatos e movimentos ambientalistas também passaram a se opor a acordos regionais abrangentes (ROETT, 2000, p. 118). Além disso, os republicanos ganharam o controle do Congresso e passaram a hostilizar diversas políticas do presidente Clinton, negando-Ihe em 1997 e 1998 o fast track, instrumento fundamental para a negociação4.

Após a ratificação do Nafta houve longa pausa na assinatura de acordos de livre-comércio entre os Estados Unidos e países da América Latina. Somente a partir de 2005 foram firmados novos tratados, com Chile, os países da América Central e a República Dominicana. Mas, então, o contexto político na Argentina era totalmente diferente, com a derrota eleitoral dos liberais e ascensão dos nacionalistas no governo Néstor Kirchner.

40 fast track é uma autorização do Legislativo dos Estados Unidos para que o Executivo negocie acordos comerciais sem emendas ou alterações por parte do Congresso, que se limita a aprová-lo ou rejeitá-lo. Clinton nunca conseguiu obtê-la. George W. Bush a recebeu, mas com diversas restrições, na área agrícola. 
As hesitações de Washington frustraram os realistas periféricos, mas a ideia do Nafta/ ALCA em contraposição ou complementação ao Mercosul continuou presente durante toda a década de 1990, dividindo a liderança política e a burocracia argentina. Foi a controvérsia mais grave na formulação da política externa, o que levou alguns de seus críticos a classificá-la de "incoerente" ou "esquizofrênica" (ONUKI, 2002). Os maiores entusiastas da adesão ao livre-comércio com os Estados Unidos estavam no Ministério da Economia, capitaneado por Cavallo, ao passo que a integração sul-americana era um tema especialmente caro ao Ministério das Relações Exteriores e ao próprio Menem (BERNAL-MEZA, 2002; VAZ, 2002).

A agenda comercial dos anos 1990 não incluía apenas questões relativas à troca de mercadorias. À medida que crescia em importância o comércio de serviços, os países centrais pressionavam pela implementação de normas sobre patentes e propriedade intelectual, tanto no sistema GATT/OMC quanto no âmbito bilateral. No caso da Argentina, isso levou a conflitos envolvendo as leis farmacêuticas e empresas americanas operando no país.

A questão atravessou a década. Embora a Argentina se adequasse às normas do GATT/OMC, o lobby farmacêutico em Washington havia conseguido regras ainda mais rigorosas na legislação americana. Os governos Bush Sênior e Clinton pressionaram Menem para que a regulação argentina se desse de acordo com os padrões estadunidenses. A princípio, a reação das autoridades menemistas foi favorável às determinações dos Estados Unidos. Di Tella usou uma de suas metáforas favoritas: "o patenteamento farmacêutico é o preço que devemos pagar para ingressar no Clube do Ocidente" (DI TELLA apud CORIGLIANO, 2003a, p. 114).

No entanto, a reação da indústria farmacêutica argentina foi muito forte e conseguiu reverter a posição do governo. Durante o conflito, Cavallo acusou a confederação desse setor de provocar danos às relações com Washington, mas o Congresso foi mais simpático a tais demandas. A normativa internacional do GATT/OMC também ampliou o espaço de manobra do governo, permitindo aos diplomatas cogitar a possibilidade de levar os Estados Unidos ao Mecanismo de Soluções de Controvérsias caso aplicassem sanções comerciais unilaterais.

Se as relações comerciais entre a Argentina e Estados Unidos foram marcadas mais por frustrações do que por sucessos, a questão dos investimentos foi bem mais recompensadora para o governo Menem. 0 tema foi onipresente nos discursos do presidente a interlocutores americanos e forneceu a base para as mudanças no campo da segurança internacional, sempre justificando essas transformações com o propósito de conquistar a confiança do mercado financeiro.

Tais esforços foram bem-sucedidos. Na década de 1980 os americanos haviam investido US\$5,85 bilhões na Argentina. Ao longo dos anos 1990, o total chegou a US\$67,6 bilhões, tornando os Estados Unidos o maior investidor externo no país, com cerca de 1/3 do montante total. Ainda assim, os capitais americanos na Argentina representaram em média somente 10\% do que os Estados Unidos investiram na América Latina. O auge foi em meados da década, com os números caindo com o fim das privatizações e após as crises financeiras internacionais (SIDICARO, 2002, p.187-8; NORDEN e RUSSELL, 2002, p. 77). 


\section{Segurança internacional}

O aspecto econômico da política externa de Menem em grande medida completou o programa liberalizante iniciado pela ditadura de 1973-1983. Contudo, a agenda de segurança internacional foi muito diferente daquela adotada pelos militares. O realismo periférico abandonou as posturas confrontacionistas do passado e engajou a Argentina nos arranjos multilaterais, como tratados de desarmamento e controle de armas. 0 país apoiou as principais operações bélicas de Washington e chegou mesmo a solicitar sua inclusão como aliado formal na OTAN. No entanto, houve discordâncias significativas no campo das chamadas "novas ameaças" como o terrorismo e o narcotráfico.

A chancelaria foi um ator fundamental para a renovação do papel dos militares, que a princípio resistiram às mudanças (DIAMINT, 2001, p. 124). O contexto internacional com o qual o governo Menem se deparou era favorável a essa adaptação. A Guerra Fria havia acabado. Não havia mais apoio externo para as ideologias de segurança nacional que serviram de respaldo à repressão política nas décadas anteriores. 0 mundo experimentava momento de grandes expectativas nos mecanismos de cooperação da ONU, sobretudo na primeira metade da década de 1990. As antigas rivalidades da América do Sul, entre Argentina, Brasil e Chile, deram lugar a processos de integração regional.

O período de 1989 a 1991 foi o da transição da Argentina para o novo paradigma de segurança internacional. Para o governo Menem, os marcos mais importantes nesse processo foram a invasão do Panamá e a Guerra do Golfo. Em 1989, os Estados Unidos ocuparam o Panamá e prenderam o presidente Manuel Noriega. O ditador havia iniciado sua carreira como colaborador dos serviços de espionagem americanos, mas havia se tornado um aliado incômodo e montado um grande esquema de crime organizado.

Apesar da retórica de alinhamento do realismo periférico, a Argentina manteve sua tradicional postura não intervencionista durante a crise do Panamá, ficando ao lado dos demais países da América Latina, que temiam mais o unilateralismo americano do que as atividades ilícitas de Noriega.

Mas a atitude do governo argentino na Guerra do Golfo foi bem diferente. Quando Saddam Hussein invadiu o Kuwait em 1990, as autoridades menemistas viram uma oportunidade de ouro para colocar em prática sua doutrina do alinhamento com Washington. Os realistas periféricos consideravam um erro-chave a não adesão aos Aliados na Segunda Guerra Mundial (ESCUDÉ, 1983). Agora o país tinha a possibilidade de cerrar fileiras ao lado dos Estados Unidos e definir seu alinhamento à nova ordem internacional em gestação.

Menem enviou dois navios de guerra ao Golfo Pérsico, num momento em que o Conselho de Segurança da ONU ainda não havia aprovado a ação militar contra o Iraque. A determinação do presidente e o apoio das Forças Armadas foram fundamentais na batalha política que se seguiu. A legalidade da escolha foi questionada, uma vez que o Congresso não foi consultado como exigia a Constituição. A rejeição ao gesto de Menem veio não só dos partidos da oposição, mas do próprio Conselho Nacional do Partido Justicialista (CORIGLIANO, 2003a).

O chanceler Cavallo afirmou que a participação no Golfo abriria oportunidades de negócios milionários junto às monarquias petrolíferas. A não intervenção significaria isolamento e 
atraso diante da nova ordem internacional. O governo venceu a disputa e o Congresso aprovou a participação das tropas como "apoio logístico" à Guerra do Golfo. O gesto foi sobretudo simbólico, devido ao reduzido número de militares argentinos na região. Não houve soldados mortos ou feridos, nem tampouco benefícios econômicos advindos do engajamento no conflito.

Ao longo da presidência de Menem, a Argentina atuou em 20 operações de paz da ONU, tornando-se o nono país em termos de contribuição militar nas Nações Unidas. Tais esforços mobilizaram cerca de $25 \%$ dos integrantes das Forças Armadas e tiveram diversas repercussões positivas 5 :

1) Deram aos militares uma nova função política, que contribuiu para a aproximação com a comunidade internacional, com impactos favoráveis para a autoimagem das Forças Armadas;

2) Os soldos extras pagos pela ONU, em dólares, eram importante benefício econômico num momento em que os funcionários públicos - inclusive os militares - passavam por restrições oriundas dos cortes dos gastos governamentais;

3) A participação nas missões das Nações Unidas em conjunto com tropas dos países desenvolvidos atualizou as Forças Armadas da Argentina em termos de treinamento e desempenhou papel importante na redução das tensões com os soldados britânicos (ainda por conta do contencioso sobre as ilhas Malvinas), com quem os argentinos conviveram pacificamente em várias operações.

Das missões em que a Argentina participou, a que melhor sinalizou o alinhamento com Washington e com os novos pressupostos da ONU foi a intervenção no Haiti, em 1994. JeanBertrand Aristide havia sido eleito presidente do país e deposto pouco depois por um golpe militar. Aristide, um ex-padre vinculado à Teologia da Libertação, não era bem-visto em Washington, mas o grande número de refugiados haitianos desembarcando na costa da Flórida acabou por convencer o governo americano de que era preferivel reinstalá-lo no poder e ter estabilidade no país. Os países latino-americanos temiam que a intervenção de Washington para restaurar a democracia pudesse estabelecer um precedente perigoso e se opuseram, ou se abstiveram de apoiar o processo.

A Argentina foi o único país do continente a defender a posição dos Estados Unidos e o próprio chanceler Di Tella acompanhou o presidente Aristide em seu retorno ao Haiti. Um diplomata argentino presente à ocasião destacou o entusiasmo popular com que foram recebidos na capital Porto Príncipe e afirmou que a decisão foi acertada e lançou as bases para a intensa cooperação entre Argentina, Brasil e Chile dez anos depois, na operação para estabilizar o país após a renúncia de Aristidé.

O governo argentino não poupou esforços para mostrar-se a Washington, e à comunidade internacional, como responsável e pacífico, em tudo diferente da postura confrontacionista do regime autoritário. Desmantelou projetos de desenvolvimento de tecnologia bélica avançada,

5 Rut Diamint, socióloga, professora da Universidad Torquato di Tella e ex-assessora do Ministério da Defesa. Entrevista ao autor. Buenos Aires, janeiro de 2007.

6 Palestra do embaixador Raúl Ricardes no seminário "Crisis del Estado, Regionalismo y Seguridad Internacional”. Buenos Aires, Universidad Torcuato di Tella, 25 de novembro de 2006. 
como o míssil Condor II. Assinou os tratados internacionais de desarmamento na área nuclear (na qual se firmaram importantes acordos com o Brasil), biológica e química. As medidas foram executadas apesar de considerável resistência entre os militares, sobretudo no caso do Condor II, no qual a Força Aérea investira décadas de pesquisa. A Argentina desarmada atendia não só aos padrões demandados pelos Estados Unidos, mas também aos objetivos domésticos do governo Menem - retirar poder dos militares. Um país sem armamentos sofisticados não poderia lançar-se em novas aventuras bélicas, como as que no passado haviam sido empreendidas contra o Chile e o Reino Unido (CAMILIÓN, 1999).

Tais medidas de desarmamento e "construção da confiança" ocorreram em diversos países da América Latina nos anos 1990 e se adequaram às políticas preconizadas pelos Estados Unidos para a região. Nacionalistas as criticaram como o abandono de estratégias de desenvolvimento importantes para adquirir autonomia tecnológica na área de defesa e resistir a pressões externas (GUIMARÃES, 2005, p. 358).

As medidas de desarmamento não impediram diversas autoridades argentinas de se envolverem num escândalo de tráfico de armas para a Croácia e o Equador - então sob embargo internacional - que culminaria em 2000 com a prisão domiciliar, por um breve momento, do próprio Menem. 0 filho do presidente foi morto num acidente de helicóptero, sob o qual pesam suspeitas de ter sido na realidade um assassinato relacionado ao caso. Outro fato tenebroso do período foi a explosão da fábrica militar na cidade de Rio Tercero, na província de Córdoba, aparentemente para encobrir indícios de tráfico de armas?

Em 1996, Menem pediu a Clinton uma aliança militar formal com os Estados Unidos, lembrando o apoio concedido nas crises do Golfo e do Haiti. A Argentina obteve a qualificação de "Aliado Extra-OTAN" por parte de Washington. O status é concedido a poucos países: Japão, Coréia do Sul, Austrália, Nova Zelândia, Israel, Egito e Jordânia. Basicamente significa a possibilidade de comprar dos americanos material militar usado em condições vantajosas e a chance de participar em algumas pesquisas científicas e concorrências da indústria bélica (TOKATLIAN, 2004, p. 176-7).

O governo considerou a nova condição uma vitória importante, ruptura com o passado em que o país era visto como não confiável, pois entre 1982 e 1989 a Argentina sofreu um embargo que proibia a compra de armas americanas. As sanções foram retiradas a pedido do presidente Menem, apesar de alguma oposição de grupos de direitos humanos no Congresso dos Estados Unidos, que protestavam em função do indulto do governo argentino aos militares (NORDEN e RUSSELL, 2002).

Também em 1996, Washington eliminou a necessidade de visto para cidadãos argentinos visitarem o país, distinção que não se aplicava a nenhum outro país da América Latina e parecia confirmar a crença da Argentina de que a nação estava destinada a ingressar no "Clube do Ocidente". A dispensa do visto durou poucos anos. Os Estados Unidos cancelaram a medida por problemas de segurança, pois passaportes argentinos - autênticos ou falsificados - teriam se tornado ferramenta para o crime organizado ou pessoas desejosas de entrar ilegalmente no território americano.

7 Bons resumos das investigações estão em "Menem condenado por contrabando de armas a Ecuador y Croacia”, La Nación, 8/3/2013 e "Sobreseyeron a Carlos Menem por la explosión de la fábrica de armas en Río Tercero", La Nación, 12/2/2014. 
Em 1999, a Argentina solicitou ingressar na OTAN. O pedido foi feito após a Guerra no Kosovo. Na análise do então secretário de Planejamento Estratégico da Presidência, Jorge Castro, o conflito havia aberto possibilidades de atuação para a Aliança que diferiam em muito do propósito original, de combater a União Soviética. O novo cenário internacional oferecia à Argentina a chance de se integrar à organização. ${ }^{8}$

Roberto Russell destaca os motivos de política doméstica que inspiraram a decisão. Em 1999 o segundo mandato de Menem chegava ao fim. A situação econômica havia piorado muito, mas o presidente ainda sonhava com a possibilidade de mais um período no cargo. A adesão à OTAN teria grande impacto junto à opinião pública e seria uma prova de que a Argentina reforçava sua posição de aproximação ao mundo desenvolvido9. Mas o pedido foi rechaçado pela instituição, sob alegação que o pertencimento à aliança estava restrito aos países do hemisfério norte.

Argentina e Estados Unidos lograram muitos entendimentos nos temas tradicionais da agenda de segurança. Mas o combate às "novas ameaças" do narcotráfico e do terrorismo foi marcado por divergências entre os dois países e por profundas divisões na sociedade argentina. Esses pontos exemplificam o impacto das fraturas decorrentes do traumático regime militar e também as dificuldades diplomáticas provocadas pelos escândalos de corrupção.

O narcotráfico se tornou uma questão para a política externa dos Estados Unidos nos anos de 1970 e foi tomando crescentemente a forma de ações militares nos países da região andina que são os grandes produtores mundiais de cocaína, como Colômbia, Peru e Bolívia. Na década de 1990, esses problemas estavam principalmente sob a responsabilidade das Forças Armadas americanas, através do seu "Comando Sul" - o ponto cardeal não se refere à porção austral dos Estados Unidos, mas à América Latina e ao Caribe. Os militares do Pentágono começaram a pressionar seus colegas latino-americanos para se envolverem diretamente no combate ao tráfico de drogas, o que foi realizado em diversos países, em especial Colômbia, México e Peru (RODRIGUES, 2012).

As mesmas propostas foram feitas à Argentina, mas dividiram o governo. 0 padrão se assemelhava a outros conflitos: Menem e Cavallo defendiam as posturas mais pró-Estados Unidos e apoiavam a ideia de criar uma força internacional contra o narcotráfico ou mesmo se engajar numa operação de apoio ao Plano Colômbia, o bilionário programa de apoio militar negociado durante o governo dos presidentes Bill Clinton e do colombiano Andrés Pastrana (1998-2002).

O governo argentino votou com Washington na ONU em diversos temas ligados ao narcotráfico, mas nunca colocou suas Forças Armadas na luta contra esse crime, como fizeram os países andinos. A ideia despertou a ojeriza dos ministros da Defesa, de boa parte dos funcionários da chancelaria e dos principais partidos. Os traumas da ditadura militar ainda estavam muito presentes e havia repúdio em aceitar o envolvimento das Forças Armadas numa atividade que as levaria a perseguir civis e as exporia ao risco de corrupção em grande escala. O ex-presidente Alfonsín resumiu a situação: "poderia nos aproximar seriamente de uma nova teoria de segurança nacional, cujos efeitos já padecemos" (Apud CORICLIANO, 2003a, p. 61).

8 Castro, entrevista ao autor. Buenos Aires, 2007.

9 Russell, entrevista ao autor. Buenos Aires, 2007. 
O caso do terrorismo foi mais complexo. A Argentina foi um dos poucos países da América do Sul a ter problemas sérios nesse aspecto na década de 1990, quando Buenos Aires sofreu dois grandes atentados atribuídos ao Hezbollah. Em 1992, bombas destruíram a embaixada de Israel na cidade. Em 1994, o alvo foi a sede da AMIA, principal organização judaica da Argentina. Os dois atentados deixaram 107 mortos e centenas de feridos.

Apesar das declarações de repúdio ao terrorismo por parte do governo argentino, pouco foi feito para investigar os crimes e prender os culpados. As pressões dos Estados Unidos e de Israel foram consideráveis, mas a reação das autoridades argentinas foi marcada pela lentidão e por suspeitas de corrupção. Diversos altos funcionários do Executivo e do Judiciário foram acusados de receber dinheiro do Irã para dificultar as investigações (LIFSITZ, 2001).

Em 1998, funcionários iranianos foram expulsos da Argentina e as disputas envolvendo os dois países continuariam muitos anos após o término do governo Menem, e envolveriam até ordem de prisão internacional contra o ex-presidente do Irã, Ali Rafsanjani, por seu envolvimento no atentado.

Em resumo, a política de segurança internacional do realismo periférico mostra um notável grau de aproximação com os Estados Unidos. Embora não tenha consistido em alinhamento integral, foram resolvidos diversos contenciosos entre os dois países. A Argentina havia se consolidado como um participante na nova ordem mundial ao lado das normas elaboradas pelas potências centrais, embora a um preço significativo decorrente da distância de outros países da América do Sul, em particular com o Brasil. Os custos foram contrabalanceados pela diminuição das tensões entre civis e militares, que encontraram novas funções e perderam poder econômico e político.

\section{Conclusão}

O pilar do realismo periférico era o alinhamento da Argentina com os Estados Unidos. 0 exame das principais questões da relação entre os dois países mostra que de fato o governo Menem promoveu significativa aproximação, abandonando os confrontos pendentes entre ambas as nações. As reformas pró-mercado atenderam aos padrões do Consenso de Washington, a divida externa foi renegociada, melhorou o fluxo de comércio e o de investimentos e se alcançou amplo nivel de cooperação na segurança internacional.

Contudo, persistiram divergências importantes em muitos aspectos. As exportações argentinas ao mercado americano continuaram limitadas e sujeitas a barreiras como subsídios e cotas. Não se chegou a um acordo quanto às patentes farmacêuticas e o governo Menem não conseguiu a inserção num tratado de livre-comércio com Washington, nem a adesão à OTAN.

A cooperação no combate ao narcotráfico e nos temas de segurança internacional foi restrita pela relutância em engajar as Forças Armadas em atividades policiais, mas também pela fragilidade do sistema policial e judiciário da Argentina, pelos interesses políticos no Oriente Médio e pela própria corrupção das autoridades.

Isto significa que o alinhamento da Argentina com os Estados Unidos ocorreu, mas nunca foi automático nem completo. Em diversos momentos a oposição da sociedade e de 
setores da burocracia fizeram com o que o governo Menem revisse suas propostas e alterasse suas posições. Em outras ocasiões, a própria liderança política argentina optou por assumir comportamentos divergentes de Washington. A política externa foi mais moderada do que deu a entender a retórica, em especial os pronunciamentos exaltados do chanceler Guido di Tella.

Os resultados econômicos advindos da aplicação da doutrina do realismo periférico também foram matizados. Os principais ganhos oriundos da aproximação com os Estados Unidos foram a renegociação da dívida e o aumento do fluxo de investimentos para a Argentina. Entre a implementação da conversibilidade e meados da década de 1990 houve anos de aumento acelerado do PIB, inflação sob controle e um boom de euforia consumista resultante do dólar barato e da abertura comercial. No entanto, essa prosperidade era em larga medida ilusória e de curto prazo. O déficit comercial era uma bomba-relógio que só se sustentaria enquanto houvesse grande fluxo de capitais para o país, como durante as privatizações. A boa vontade do governo americano e do FMI mascararam problemas estruturais sérios, como o aprofundamento da dívida pública.

As crises financeiras que atingiram os países em desenvolvimento e a Rússia na segunda metade dos anos 1990 mudaram esse quadro de forma dramática e revelaram a fragilidade econômica argentina. A explosão da crise também revelou a falácia da ideologia que afirmava que a Argentina voltava a fazer parte do Primeiro Mundo. 0 país que foi às ruas em 2001 estava mais desigual e com mais pobres, em tudo semelhante aos vizinhos da América Latina e não ao "Clube do Ocidente" almejado por alguns de seus líderes políticos.

\section{Referências}

BERNAL-MEZA, Raul. 2002 "Política Exterior Argentina: De Menem a De La Rúa. Hay una nueva política? São Paulo em Perspectiva, v. 16 n. 1, p. 74-93.

BLUSTEIN, Paul. 2005. And the Money Kept Rolling In (And Out) - Wall Street, the IMF and the bankrupting of Argentina. Nova York: Public Affairs.

CAMILIÓN, Oscar. 1999. Memórias Políticas: de Frondizi a Menem. Buenos Aires: Planeta.

CISNEROS, Andrés e PIÑEIRO IÑIGUEZ Carlos. 2002. Del ABC al Mercosur: la integración latinoamericana en la doctrina y praxis del peronismo. Buenos Aires: Grupo Editor Latinoamericano.

CORIGLIANO, Francisco. 2003a. "La Dimensión Bilateral de las Relaciones entre Argentina y Estados Unidos Durante la Década de 1990: el ingreso al paradima de 'relaciones especiales’”. In: C. Escudé (org.) História General de las Relaciones Exteriores de la República Argentina - Tomo XV - Las 'Relaciones Carnales', los vínculos políticos com las grandes potencias, 1989-2000.

2003b. “La Dimensión Multilateral de las Relaciones entre Argentina y Estados Unidos Durante la Década de 1990: el ingreso al paradima de 'relaciones especiales". In: C. Escudé (org.) História General de las Relaciones Exteriores de la República Argentina - Tomo XV - Las 'Relaciones Carnales', los vínculos políticos com las grandes potencias, 1989-2000.

DE LA BALZE, Felipe. 2000. "El Destino del Mercosur: entre la unión aduanera y la 'integración imperfecta”". In: F. de la Balze (org.) El Futuro del Mercosur: entre la retórica y el realismo. Buenos Aires: CARI/ABIA. 
1997. "La Política Exterior em Tres 'Tiempos': Ios fundamientos de la 'nueva política exterior' “. In: F. De La Balze e E. Roca (orgs) Argentina y Estados Unidos: fundamientos de una nueva alianza. Buenos Aires: ABRA/CARI.

1995. "Argentina y Brasil: enfrentando el siglo XXI". In: F. De La Balze e E. Baldinelli (orgs) Argentina y Brasil: enfrentando el siglo XXI. Buenos Aires: ABRA.

DIAMINT, Rut. 2001. “Debates sobre Política de Seguridad em Argentina”. In: R. Diamint (org.) La OTAN y los Desafíos en el Mercosur". Buenos Aires: Grupo Editor Latinoamericano.

ESCUDĖ, Carlos. 1992. Realismo Periférico. Buenos Aires: Planeta.

1983. Gran-Bretaña, Estados Unidos y la Declinación Argentina. Buenos Aires: Fundación Editorial Belgrano.

FERRER, Aldo. 1998. El Capitalismo Argentino. Buenos Aires: Fondo de Cultura Economica.

GUIMARÃES, Samuel Pinheiro. 2005. Desafios Brasileiros na Era dos Gigantes. Rio de Janeiro: Contraponto.

LIFSITZ, Ester. 2001. Política Exterior Argentina Durante el Menemismo: el caso de Israel. Tese de licenciatura apresentada à Faculdade de Relações Internacionais, Universidad Torcuato di Tella, Buenos Aires.

MINISTÉRIO DAS RELAÇÕES EXTERIORES, COMÉRCIO INTERNACIONAL E CULTO DA ARGENTINA. 1999. Sintesis Informativa Período 1989-1999.

MONIZ BANDEIRA, Luiz Alberto. 2003. Brasil, Argentina e Estados Unidos: da tríplice aliança ao Mercosul. Rio de Janeiro: Ed. Revan.

NORDEN, Deborah e RUSSELL, Roberto. 2002. United States and Argentina: changing relations in a changing world. Nova York: Routledge.

ONUKI, Janina. 2002. As Mudanças da Política Externa Argentina no Governo Menem (1989-1999). Tese de doutorado apresentada à Faculdade de Filosofia, Letras e Ciências Humanas da Universidade de São Paulo.

RAPOPORT, Mario. 2006. El Viraje del Siglo XXI: deudas y desafios en la Argentina, América Latina y el Mundo.

RICUPERO, Rubens. 2003. A ALCA. São Paulo: Publifolha.

RODRIGUES, Thiago. 2012. Narcotráfico: uma guerra na guerra. São Paulo: Desatino. $2^{a}$ edição.

ROETT, Riordan. 2000. "La Política Estadunidense, el futuro del ALCA y del Mercosur". In: F. De la Balze (org) El Futuro del Mercosur: entre la retórica y el realismo. Buenos Aires: CARI-ABA.

RUSSELL, Roberto e TOKATLIAN, Juan Gabriel. 2003. El Lugar de Brasil en la Política Exterior Argentina. Buenos Aires: Fondo de Cultura Economica.

SACCONE, Maria Alejandra. 1994. "Aspectos politico-diplomaticos de uma nueva prioridad em la política exterior argentina: el Mercosur". In: A. Busso e A Bologna. (orgs.) La Política Exterior del Cobierno Menem. Rosário: Ed. CERIR.

SIDICARO, Ricardo. Los Tres Peronismos. 2002. Buenos Aires: Siglo XXI.

TOKATLIAN, Juan Gabriel. 2004. “El Proyecto de Reordenamiento Mundial de Estados Unidos: una mirada crítica." In: M. Hirst (org) Império, Estados e instituiciones: la política internacional em los comienzos del siglo XXI. Buenos Aires: Altamira.

WALT, Stephen. 1987. The Origins of Alliances. Ithaca: Cornell University Press.

VAZ, Alcides. 2002. Cooperação, Integração e Processo Negociador: a formação do Mercosul Brasília: IPRI. 